\title{
Presence of autoantibodies in "seronegative" rheumatoid arthritis associates with classical risk factors and high disease activity
}

Evan Reed ${ }^{1}$, Anna Karin Hedström²,3, Monika Hansson ${ }^{1}$, Linda Mathsson-Alm²,5, Boel Brynedal'2, Saedis Saevarsdottir ${ }^{1,6,7}$, Martin Cornillet ${ }^{8}$, Per-Johan Jakobsson ${ }^{1}$, Rikard Holmdahl ${ }^{9}$, Karl Skriner ${ }^{10}$, Guy Serre ${ }^{8}$, Lars Alfredsson ${ }^{2,3,11}$, Johan Rönnelid ${ }^{5}$ and Karin Lundberg ${ }^{1^{*}}$ (D)

\begin{abstract}
Background: Rheumatoid arthritis (RA) is classified as seropositive or seronegative, depending on the presence/ absence of rheumatoid factor (RF), primarily lgM RF, and/or anti-citrullinated protein antibodies (ACPA), commonly detected using anti-cyclic citrullinated peptide (CCP) assays. Known risk factors associate with the more severe seropositive form of RA; less is known about seronegative RA. Here, we examine risk factors and clinical phenotypes in relation to presence of autoantibodies in the RA subset that is traditionally defined as seronegative.

Methods: Anti-CCP2 IgG, 19 ACPA fine-specificities, IgM/lgG/lgA RF, anti-carbamylated-protein (CarP) antibodies, and 17 other autoantibodies, were analysed in 2755 RA patients and 370 controls. Antibody prevalence, levels, and co-occurrence were examined, and associations with risk factors and disease activity during 5 years were investigated for different antibody-defined RA subsets.
\end{abstract}

Results: Autoantibodies were detected in a substantial proportion of the traditionally defined seronegative RA subset, with ACPA fine-specificities found in 30\%, IgA/lgG RF in 9.4\%, and anti-CarP antibodies in 16\%, with a 9.6\% co-occurrence of at least two types of RA-associated autoantibodies. HLA-DRB1 shared epitope (SE) associated with the presence of ACPA in anti-CCP2-negative RA; in anti-CCP2-positive RA, the SE association was defined by six ACPA fine-specificities with high co-occurrence. Smoking associated with RF, but not with ACPA, in anti-CCP2-negative RA. Presence of ACPA and RF, but not anti-CarP antibodies, in conventionally defined "seronegative" RA, associated with worse clinical outcome.

Conclusions: "Seronegative" RA is not truly a seronegative disease subset. Additional screening for ACPA fine-specificities and IgA/lgG RF defines a group of patients that resembles seropositive patients with respect to risk factors and clinical picture and may contribute to earlier diagnosis for a subset of anti-CCP2-/IgM RF- patients with a high need for active treatment.

\footnotetext{
* Correspondence: Karin.Lundberg@ki.se

'Division of Rheumatology, Department of Medicine Solna, Karolinska Institutet, Karolinska University Hospital, CMM L8:04, 17176 Stockholm, Sweden

Full list of author information is available at the end of the article
}

C C The Author(s). 2020 Open Access This article is licensed under a Creative Commons Attribution 4.0 International License, which permits use, sharing, adaptation, distribution and reproduction in any medium or format, as long as you give appropriate credit to the original author(s) and the source, provide a link to the Creative Commons licence, and indicate if changes were made. The images or other third party material in this article are included in the article's Creative Commons licence, unless indicated otherwise in a credit line to the material. If material is not included in the article's Creative Commons licence and your intended use is not permitted by statutory regulation or exceeds the permitted use, you will need to obtain permission directly from the copyright holder. To view a copy of this licence, visit http://creativecommons.org/licenses/by/4.0/ The Creative Commons Public Domain Dedication waiver (http://creativecommons.org/publicdomain/zero/1.0/) applies to the data made available in this article, unless otherwise stated in a credit line to the data. 
(Continued from previous page)

Keywords: Rheumatoid arthritis (RA), Autoantibodies, Anti-citrullinated protein antibodies (ACPA), Cyclic citrullinated peptide (CCP), Rheumatoid factor (RF), Anti-carbamylated protein antibodies (anti-CarP), Disease activity score for 28 joints (DAS28), HLA-DRB1 shared epitope (SE), Smoking

\section{Introduction}

Presence of anti-citrullinated protein antibodies (ACPA) is a hallmark of rheumatoid arthritis (RA), and together with rheumatoid factor (RF), part of the 2010 American College of Rheumatology (ACR)/European League Against Rheumatism (EULAR) classification criteria [1]. Patients positive for ACPA and/or RF may be referred to as "seropositive" and make up approximately two thirds of the RA population. Seropositive and seronegative RA seem to have disparate mechanisms in predisposition, since HLA-DRB1 shared epitope (SE) alleles, as well as a number of other genes, associate primarily with ACPApositive RA [2, 3], while other genes have been linked to ACPA-negative disease [4], suggesting that these subsets are partly separate disease entities.

While typically considered having a less inflammatory and less destructive form of RA [5], seronegative patients require more clinical symptoms to be classified as having RA according to the 2010 ACR/EULAR criteria [1], compared to seropositive patients, and may consequently be diagnosed later [6]. Since all patients benefit from early treatment, early diagnosis is critical also for seronegative patients [7-9]. A major obstacle to this is the lack of biomarkers.

ACPA status is commonly determined using assays based on cyclic citrullinated peptides (CCP), such as the "second generation" CCP2 test. However, these tests utilise synthetic peptides as surrogate markers for in vivo citrullinated antigens, while recent years have seen a number of studies describing ACPA targets on defined proteins (e.g. citrullinated fibrinogen [10], vimentin [11], collagen type II (CII) [12], $\alpha$-enolase [13], histones [14], and tenascin C [15]). Since the CCP2 test does not capture all ACPA, multiplex assays capable of detecting multiple ACPA fine-specificities simultaneously may be useful, as more patients could potentially be categorised as ACPA-positive/seropositive [14, 1619]. Using such a multiplex citrullinated peptide array, we have recently shown that $16 \%$ of anti-CCP2-negative RA patients were in fact ACPA-positive [19].

The other major autoantibody in RA, RF, is most often defined as IgM directed against the constant region of IgG, although other RF isotypes (mainly IgG and IgA) are also present in subsets of patients, but generally not screened for in the clinic [20]. More recently, antibodies to carbamylated proteins (anti-CarP antibodies) have been described in RA [21], and additional autoantibodies, including anti-nuclear antibodies, which are primarily linked to other rheumatic/autoimmune conditions, have also been detected in subsets of RA [22].

In this study, we have used the Swedish populationbased RA case-control study EIRA (Epidemiological Investigation of RA) as a basis for the analysis of autoantibodies present in the RA subset conventionally defined as seronegative, and we have investigated whether the presence of such antibodies associates with classical RA risk factors and have predictive value for disease activity.

\section{Patients and methods Study population}

This study includes newly diagnosed RA based on the 1987 revised ACR criteria [23] and age-, sex-, and residential area-matched controls from the Swedish population-based EIRA cohort [24]. Information on smoking was collected via self-reported questionnaire at baseline; individuals were categorised as "ever smokers" (including current and former smokers) or "never smokers". Patients and controls donated blood at inclusion and were genotyped for HLA-DRB1 alleles and PTPN22 (rs2476601) polymorphism as previously described [25, 26]. HLA-DRB1*01 (except DRB1*0103), *04, and *10 were classified as SE. Data on smoking and genetics were available for 2198 RA patients and 2797 controls. Baseline disease activity score for 28 joints (DAS28) and C-reactive protein (CRP) levels (mg/L) were captured on 1986 and 2096 RA patients, respectively, by linking EIRA with the Swedish Rheumatology Quality register [27]. Five-year clinical follow-up data (DAS28-CRP) was analysed in 1086 RA patients.

This study has been performed in compliance with the Declaration of Helsinki, with informed consent obtained from all participants, and ethical approval granted at the Regional Ethical Review Board in Stockholm.

\section{Antibody detection: multiplex microarray and ELISA}

High-throughput IgG screening was performed on sera from 2755 RA cases and 370 controls using a custommade microarray chip (Thermo Fisher Scientific, ImmunoDiagnostics), as previously described [18]. Antigens included 19 citrullinated peptides (and argininecontaining equivalents) from filaggrin, fibrinogen, vimentin, $\alpha$-enolase, collagen type II (CII), and heterogeneous nuclear ribonucleoprotein-A3 (hnRNP-A3), and 17 non-citrullinated antigens reported as autoantibody targets in other rheumatic/autoimmune disorders (Additional files 1 and 2). Cutoff (for each antibody) was set 
based on reactivity among controls and correspond to the highest 98th percentile found in 20 randomly selected subsets comprising $80 \%$ of the control population.

Anti-CCP2 IgG was measured using Immunoscan CCPlus ${ }^{\oplus}$ ELISA (Euro-Diagnostica AB, Malmö, Sweden), according to the manufacturer's instructions, with a cutoff of $25 \mathrm{U} / \mathrm{mL}$. IgM, IgG, and IgA RF were analysed using EliA ${ }^{\mathrm{m}}$ immunoassay on Phadia 2500 (Phadia AB, Uppsala, Sweden), using cutoff values as stated in the manufacturer's instructions. Anti-carbamylated fibrinogen antibodies were measured in a subset of patients $(n=1944)$, as previously reported [28], with cutoff set at the 98th percentile among 316 EIRA controls.

\section{Statistical methods}

Differences in antibody levels/prevalence and DAS28CRP were analysed by Mann-Whitney $U$ test. Cooccurrence of ACPA and comparison of correlation coefficients between different ACPA fine-specificities in anti-CCP2-positive and anti-CCP2-negative RA were calculated using Pearson's correlation (Rv.3.3.3), among patients that were positive for at least one ACPA finespecificity. Associations between RA subsets and risk factors were determined by unconditional logistic regression and presented as odds ratios (OR) with 95\% confidence intervals (CI) (SAS 9.4). Analyses were adjusted for age, sex, and residential area, and PTPN22, smoking, and SE when appropriate.

\section{Results}

Comparison of ACPA fine-specificities in anti-CCP2positive and anti-CCP2-negative RA

EIRA cases were first divided based on anti-CCP2 IgG status, and anti-CCP2-positive patients were younger, more frequently smokers, and carriers of HLA-DRB1 SE and PTPN22 rs2476601, while there were no differences with regard to baseline DAS28, CRP, or the female-tomale ratio, as compared to anti-CCP2-negative patients (Additional file 3).

As we have recently shown, using the multiplex citrullinated peptide array, ACPA fine-specificities can be detected in a substantial proportion (16\%) of the antiCCP2-negative EIRA RA population [19], also in line with previous data [16, 17]. In this extended analysis, we show that the pattern of citrulline-reactivity is similar for anti-CCP2-negative and anti-CCP2-positive RA, albeit with lower prevalence, levels, and co-occurrence of ACPA fine-specificities. Eleven out of 19 ACPA finespecificities were detected in anti-CCP2-negative RA, in frequencies significantly above controls, while all 19 ACPA were detected in anti-CCP2-positive RA (Table 1). The citrullinated fibrinogen-derived peptide Cit-Fibß $\beta_{60}$

Table 1 ACPA fine-specificities in anti-CCP2+ and anti-CCP-RA and controls

\begin{tabular}{|c|c|c|c|c|c|c|c|}
\hline \multirow{2}{*}{$\begin{array}{l}\text { ACPA fine- } \\
\text { specificities }\end{array}$} & \multicolumn{4}{|c|}{ Antibody frequencies (\%) } & \multicolumn{3}{|c|}{ Antibody levels (median) ${ }^{a}$} \\
\hline & $\overline{\mathrm{CCP} 2+}$ & CCP2- & Controls & $p$ value $^{b}$ & $\overline{\mathrm{CCP} 2+}$ & CCP2- & $p$ value ${ }^{c}$ \\
\hline Cit-Fibß $60-74$ & 80.6 & 9.5 & 0.8 & $<0.0001$ & 195.3 & 27.1 & $<0.0001$ \\
\hline Cit-peptide-5 & 75.4 & 8.6 & 1.1 & $<0.0001$ & 81.4 & 27.2 & $<0.0001$ \\
\hline Cit-peptide-Z1 & 69.3 & 5.1 & 0.5 & 0.0001 & 167.4 & 38.6 & $<0.0001$ \\
\hline Cit-Fibß $ß_{36-52}$ & 65.6 & 5.0 & 1.4 & 0.003 & 605.0 & 186.4 & $<0.0001$ \\
\hline Cit-Vim $60-75$ & 63.5 & 2.9 & 1.1 & 0.049 & 641.6 & 321.9 & 0.009 \\
\hline CEP-1 & 60.9 & 4.4 & 1.1 & 0.003 & 678.2 & 316.1 & $<0.0001$ \\
\hline cfc1-cyc (CCP1) & 59.9 & 3.8 & 1.1 & 0.009 & 514.7 & 166.0 & $<0.0001$ \\
\hline Cit-Fiba ${ }_{563-583}$ & 57.6 & 2.5 & 1.1 & 0.10 & 444.8 & 144.0 & 0.002 \\
\hline Cit-peptide-Z2 & 49.5 & 2.9 & 0.3 & 0.003 & 150.9 & 58.6 & 0.002 \\
\hline Cit-peptide-1 & 45.0 & 4.7 & 1.9 & 0.02 & 72.7 & 29.2 & $<0.0001$ \\
\hline Cit-Fiba $621-635$ & 42.9 & 4.6 & 1.4 & 0.005 & 384.0 & 123.0 & $<0.0001$ \\
\hline Cit-peptide-Bla26 & 39.9 & 4.4 & 1.4 & 0.006 & 80.3 & 48.7 & 0.003 \\
\hline Cit-Vim $2-17$ & 40.3 & 2.6 & 1.4 & 0.16 & 75.9 & 72.8 & 0.712 \\
\hline $\mathrm{Cit}^{-F} 4_{\left({ }_{(\mathrm{Cit}-\mathrm{Cit}}\right)}$ & 36.1 & 3.4 & 1.6 & 0.08 & 84.9 & 60.6 & 0.032 \\
\hline Cit-F4 $4_{(R-C i t)}$ & 29.9 & 2.1 & 1.4 & 0.36 & 86.4 & 80.6 & 0.366 \\
\hline Cit-Fiba ${ }_{580-600}$ & 24.2 & 2.8 & 1.4 & 0.11 & 264.2 & 197.2 & 0.024 \\
\hline Cit-Fiba $36-50$ & 17.6 & 4.0 & 1.9 & 0.053 & 422.9 & 265.5 & $<0.0001$ \\
\hline Cit-C1 & 10.8 & 1.9 & 1.4 & 0.48 & 69.3 & 87.9 & 0.383 \\
\hline $\mathrm{Cit}^{\mathrm{F}} 4_{(\mathrm{Cit}-\mathrm{R})}$ & 6.2 & 1.8 & 1.1 & 0.34 & 403.0 & 306.5 & 0.382 \\
\hline
\end{tabular}

${ }^{a}$ Median antibody levels are shown for ACPA+ patients only. $P$ values indicate differences between ${ }^{b}$ anti-CCP2- RA and controls or between ${ }^{C}$ anti-CCP2+ and anti-CCP2- RA 
74 was the most commonly detected fine-specificity in both subsets, followed by Cit-peptide- 5 and Cit-peptideZ1 derived from citrullinated hnRNP-A3 and CitFibß $\beta_{36-52}$ from fibrinogen. ACPA levels among ACPA fine-specificity positive individuals were higher in antiCCP2-positive RA, compared to anti-CCP2-negative RA (Table 1), and in anti-CCP2-negative RA, compared to controls (Additional file 4). Co-occurrence of different ACPA fine-specificities showed a similar correlation profile for anti-CCP2-positive and anti-CCP2-negative subsets $\left(r^{2}=0.65, \quad p=5.4 \mathrm{e}-22\right)$, with high correlation between most ACPA, but an independent expression pattern for some (e.g. Cit-Fibo $\alpha_{36-50}$, Cit-Peptide-1, Cit$\mathrm{F}_{\text {Cit-R }}$, and Cit-C1) (Fig. 1a, b). Co-occurrence of multiple ACPA was rare among controls; the majority (84.1\%) had only one ACPA fine-specificity, and none of the controls had more than three. The number of citrullinated peptides recognised by control sera was significantly lower than that of anti-CCP2-negative RA sera, where $15 \%$ were positive for more than three ACPA, and $32.7 \%$ were positive for two or three finespecificities (Fig. 1c, d).

\section{Presence of RF in anti-CCP2-positive and anti-CCP2- negative RA}

In the present study, we have also analysed RF isotypes IgM, IgG, and IgA in EIRA, and all RF isotypes were detected in the anti-CCP2-negative subset, with IgM RF present in $23.8 \%$, IgG RF in $17.4 \%$, and IgA RF in $10.6 \%$ (Fig. 2a). Higher frequencies were detected in antiCCP2-positive RA: 89.6\% (IgM RF), 75\% (IgG RF), and $56.8 \%$ (IgA RF). IgM RF levels were higher in antiCCP2-positive, compared to anti-CCP2-negative patients, while no differences were observed for $\operatorname{IgG}$ and IgA RF levels (Fig. 2b). Co-occurrence of at least two RF isotypes was $47 \%$ among $\mathrm{RF}+$ /anti-CCP2- patients, and all three isotypes were present in $25 \%$; the corresponding figures for RF+/anti-CCP2+ patients were $83 \%$ and $53 \%$, respectively (Fig. 2c). Co-occurrence of RF isotypes was rare among RF-positive controls, and RF levels were significantly lower than in patients.
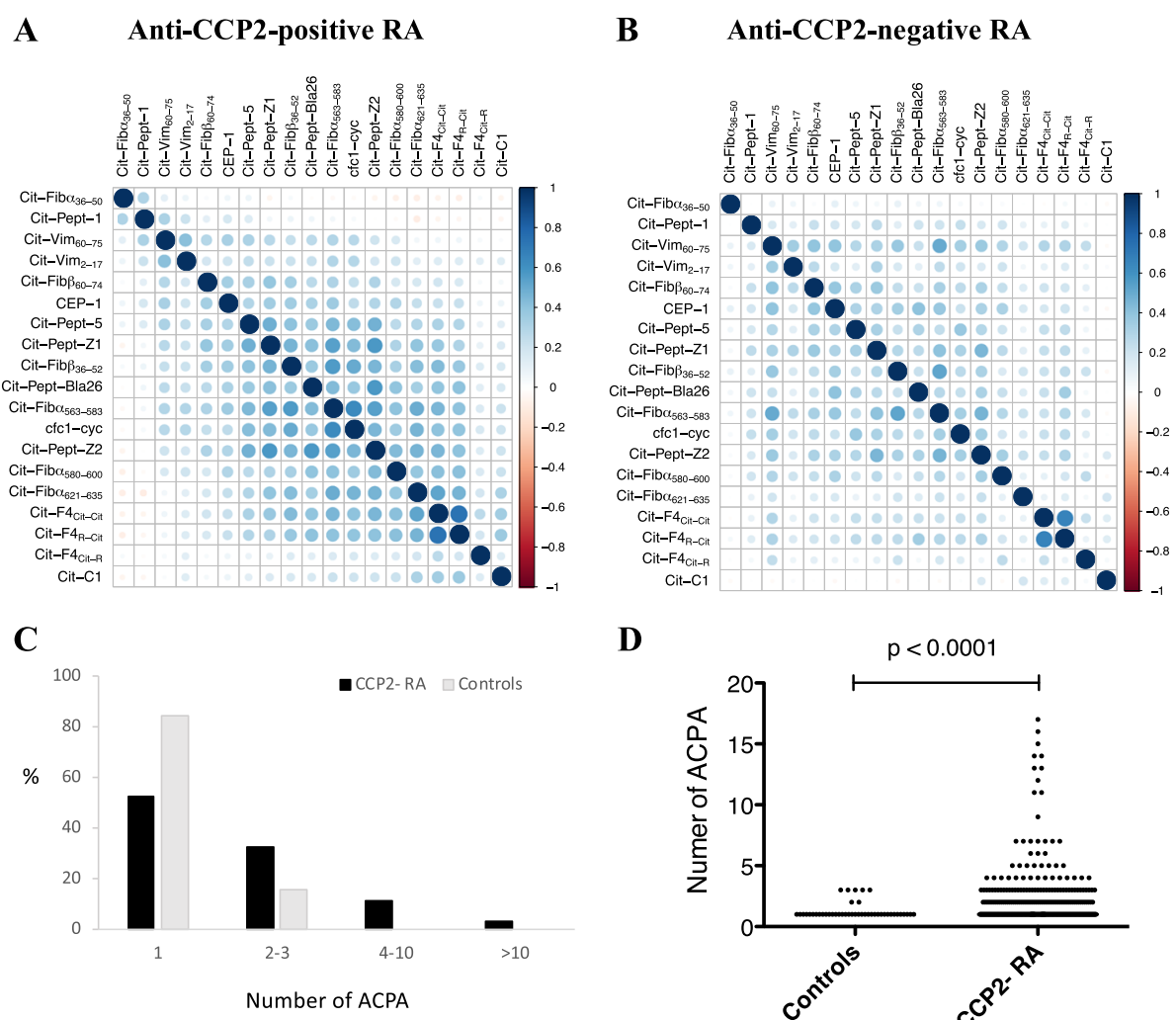

D

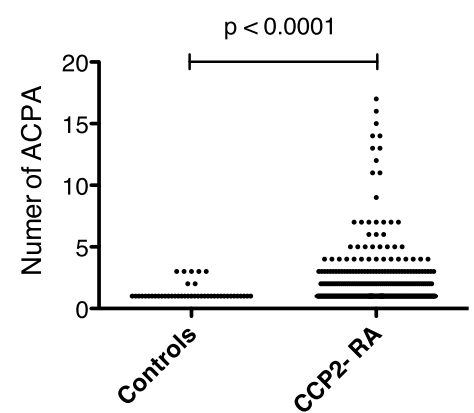

Fig. 1 Co-occurrence of ACPA fine-specificities, a, b Correlation plots illustrating co-occurrence of different ACPA fine-specificities, in anti-CCP2positive and anti-CCP2-negative RA. Correlation (Pearson $r^{2}$ ) between binary antibody expression vectors, among patients that were positive for at least one ACPA fine-specificity, are shown; plotted using corrplot (v.0.77). The degree of correlation is illustrated in colours, according to Pearson's correlation coefficient (scale shown on the right). $\mathbf{c}$, $\mathbf{d}$ The number of ACPA fine-specificities in anti-CCP2-negative RA and controls. The frequency (\%) of anti-CCP2-negative RA patients and controls with 1, 2-3, 4-10, or > 10 ACPA fine-specificities, and the number of ACPA per individual patient/control, are shown. Only ACPA-positive individuals with higher reactivity against citrulline compared to arginine-containing peptides were included in the analysis 


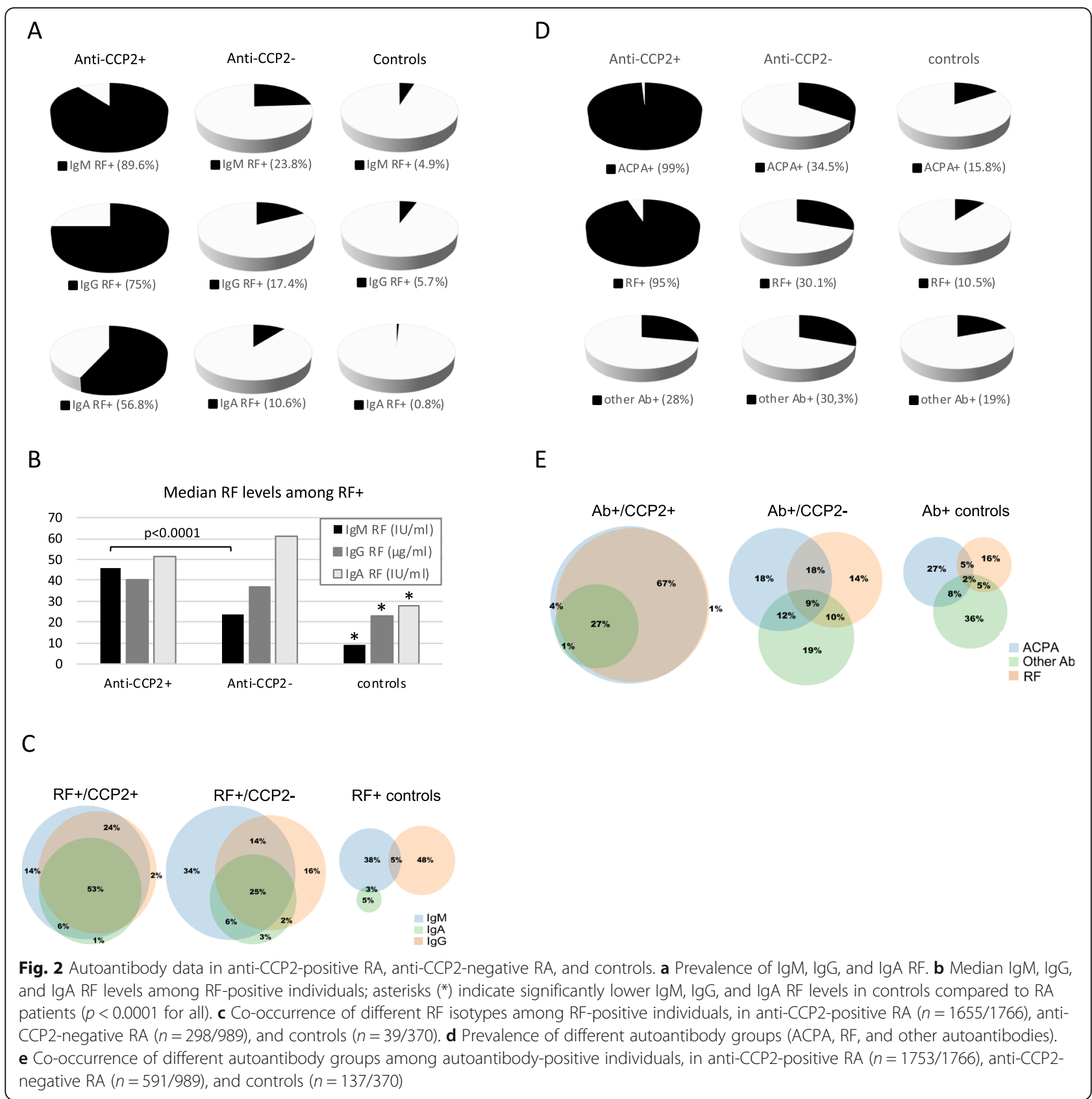

\section{Presence of other autoantibodies in anti-CCP2-positive} and anti-CCP2-negative RA

In addition to ACPA fine-specificities and RF isotypes, we have screened for the presence of 17 autoantibodies primarily associated with other autoimmune rheumatic diseases. In general, these other autoantibodies were present at low frequencies in EIRA, with small differences between anti-CCP2-positive and anti-CCP2negative patients (Additional file 5). Six out of 17 (Ro60/ SSA, Ro52/SSA, PMScl100, La/SSB, U1-RNP-C, and CENPB) were detected at significantly higher frequencies in RA compared to controls, with antibodies against
Ro60/SSA and Ro52/SSA as the most common, both with a frequency of $5.3 \%$ in anti-CCP2-negative RA and $4.8 \%$ and $3.4 \%$, respectively, in anti-CCP2-positive RA.

\section{Narrowing the "serological gap"}

When combining ACPA, RF, and other autoantibodies, we detect autoantibodies in $59.8 \%$ of the anti-CCP2negative RA population, with ACPA fine-specificities found in $34.5 \%$, RF isotypes in $30.1 \%$, and other autoantibodies in $30.3 \%$. Notably, considering the high number of autoantibodies investigated $(n=39)$, each with an individual cutoff set between the 95th and 98th 
percentile, autoantibodies were also detected in $37 \%$ of the control population, with ACPA in $15.8 \%$, RF in $10.5 \%$, and other autoantibodies in $19 \%$. Importantly, cooccurrence of ACPA and RF was $15.7 \%$ in anti-CCP2negative RA, compared to only $2.7 \%$ in controls. For an illustration of the distribution of ACPA, RF, and other autoantibodies in anti-CCP2-positive RA, anti-CCP2negative RA, and controls, see Fig. $2 \mathrm{~d}$ and e.

\section{Autoantibodies in relation to RA risk factors} Classical RA risk factors HLA-DRB1 SE, PTPN22 polymorphism, and cigarette smoking are known to associate with the anti-CCP2-positive subset of RA [26, 29]. In addition, we and others have shown associations between $\mathrm{SE}$ and the presence of ACPA in anti-CCP2-negative RA. Here we can confirm an association between SE and ACPA+/anti-CCP2- RA, while there was no significant association between $\mathrm{SE}$ and the presence of RF or other autoantibodies in anti-CCP2-negative RA (Table 2). Smoking, on the other hand, did not associate with ACPA, or other autoantibodies, but showed a significant association with RF in anti-CCP2-negative RA. PTPN22 polymorphism associated significantly with all anti-CCP2-negative RA subsets, irrespective of autoantibody status (Additional file 6).

Based on these data, we proceeded to investigate associations between SE and individual ACPA fine-specificities further, as well as associations between smoking and different RF isotypes, in both anti-CCP2-positive and antiCCP2-negative RA subsets.
In anti-CCP2-positive RA, SE associated with all individual ACPA fine-specificities, in line with what we have previously shown in RA [19]. In our extended analysis, we found that the SE association was significantly stronger in the presence of ACPA reactive with Cit-Fib $\beta_{60-74}$, Citpeptide-5, Cit-peptide-Z1, Cit-Vim ${ }_{60-75}$, CEP-1, and Cit$\operatorname{Vim}_{2-17}$, than in the absence of these six ACPA finespecificities (Additional file 7); two of these ACPA finespecificities (Cit-Fib $\beta_{60-74}$ and Cit-Vim $60-75$ ) also showed significant associations with SE in anti-CCP2-negative RA.

The association with smoking was significantly stronger in the presence of IgG and IgA RF in anti-CCP2positive RA and in the presence of IgM and IgA RF in anti-CCP2-negative RA, than in the absence of these RF isotypes (Additional file 8). Moreover, in a sub-analysis, comparing never, current, and former smokers in the whole RA population, we observed significantly higher RF levels (all isotypes) and anti-CCP2 IgG levels in current and former smokers, compared to never smokers $(p<0.0001)$ (Additional file 9). However, when comparing current to former smokers, only RF levels (all isotypes) were significantly elevated ( $p<0.0001$ for IgM and IgA RF; $p=0.0003$ for IgG RF), while anti-CCP2 IgG levels $(p=0.1532)$ and ACPA fine-specificity levels (data not shown) did not differ significantly.

\section{Presence of RA-associated autoantibodies in "seronegative" RA}

In a subset of EIRA ( $n=1944)$, we have previously investigated the presence of anti-CarP antibodies, which we

Table 2 Associations between autoantibodies and risk factors, in anti-CCP2- RA

\begin{tabular}{|c|c|c|c|c|}
\hline \multirow[t]{2}{*}{ Subgroup } & \multicolumn{4}{|l|}{ Exposure } \\
\hline & SE- & $\mathrm{SE}+$ & OR $(95 \% \mathrm{CI})^{a}$ & OR $(95 \% \mathrm{Cl})^{\mathrm{b}}$ \\
\hline Controls & 1341 & 1456 & 1.0 (ref) & 1.0 (ref) \\
\hline ACPA- & 246 & 265 & $0.99(0.82-1.2)$ & $1.00(0.83-1.21)$ \\
\hline $\mathrm{ACPA}+$ & 126 & 176 & $1.29(1.01-1.64)$ & $\mathbf{1 . 3 0}(1.02-1.65)$ \\
\hline RF- & 258 & 293 & $1.04(0.87-1.26)$ & $1.05(0.88-1.27)$ \\
\hline$R F+$ & 114 & 148 & $1.20(0.93-1.55)$ & $1.21(0.94-1.57)$ \\
\hline Other Ab- & 242 & 316 & $\mathbf{1 . 2 0}(1.00-1.45)$ & $1.22(1.01-1.46)$ \\
\hline \multirow[t]{2}{*}{ Other Ab+ } & 130 & 125 & $0.88(0.68-1.14)$ & $0.89(0.69-1.15)$ \\
\hline & Never smoker & Ever smoker & OR $(95 \% \mathrm{CI})^{a}$ & OR $(95 \% \mathrm{CI})^{\mathrm{C}}$ \\
\hline Controls & 1208 & 1589 & 1.0 (ref) & 1.0 (ref) \\
\hline ACPA- & 184 & 327 & $1.35(1.11-1.64)$ & $\mathbf{1 . 3 4}(1.10-1.63)$ \\
\hline $\mathrm{ACPA}+$ & 121 & 181 & $1.16(0.91-1.48)$ & $1.15(0.90-1.47)$ \\
\hline RF- & 221 & 330 & $1.13(0.94-1.36)$ & $1.13(0.93-1.36)$ \\
\hline $\mathrm{RF}+$ & 84 & 178 & $1.65(1.26-2.16)$ & $1.63(1.24-2.14)$ \\
\hline other Ab- & 203 & 355 & $1.33(1.10-1.60)$ & $1.32(1.09-1.59)$ \\
\hline other Ab+ & 102 & 153 & $1.16(0.89-1.51)$ & $1.16(0.89-1.51)$ \\
\hline
\end{tabular}

Odds ratios were adjusted for ${ }^{\mathrm{a} a g e}$, sex, and residential area, ${ }^{\mathrm{b} P T P N 22}$ and smoking, or ${ }^{\mathrm{c}} \mathrm{SE}$ and PTPN22. ACPA = any ACPA fine-specificity; $R F=\operatorname{lgM}$ and/or IgG and/or IgA RF; other $A b=$ any other autoantibody 
detected in $43 \%$ of RA patients [28]. Now we focused the analysis on the traditionally defined "seronegative" subset of EIRA, i.e. anti-CCP2 IgG-/IgM RF- patients $(n=534)$, and found anti-CarP antibodies in $15.9 \%$, ACPA fine-specificities in $29.8 \%$, and IgA and/or IgG RF in $9.4 \%$, with a co-occurrence of at least two types of RA-associated autoantibodies in 9.6\% (Table 3). When combining ACPA, RF, and anti-CarP antibodies, $43.6 \%$ of the "seronegative" RA patients were in fact "seropositive".

\section{RA-associated autoantibodies in relation to disease course in "seronegative" RA}

We then investigated the impact of RA-associated autoantibodies on disease course in "seronegative" RA during a 5-year follow-up period. Compared to patients that were negative for all investigated RA-associated autoantibodies, the presence of ACPA fine-specificities and/ or IgG/IgA RF and/or anti-CarP antibodies (in the antiCCP2-/IgM RF- subset) associated with higher DAS28 during follow-up (Table 4). This observation seemed to be dependent on the presence of ACPA and RF, but not anti-CarP antibodies. Significantly higher DAS28 scores were recorded in the ACPA+/anti-CCP2-/IgM RF- subset (median DAS28: 3.66 versus 1.96, $p=0.002$ ) and in the IgA/IgG RF+/anti-CCP2-/IgM RF- subset (median DAS28: 3.17 versus $1.96, p=0.03$ ) at 48 months. Highest DAS28 was found in the ACPA+/anti-CarP-/anti-CCP2 -/IgM RF- subset (median DAS28: 3.23 versus 2.14, $p=$ 0.03 at 36 months, and 3.69 versus $1.96, p=0.007$, at 48 months). Notably, DAS28 was as high (or even higher) in this subset as in the traditionally defined seropositive subset (i.e. anti-CCP2+ and/or IgM RF+). Lowest DAS28 scores during follow-up were noted in ACPA-/antiCarP+/anti-CCP2-/IgM RF- patients.

\section{Discussion}

We find autoantibodies in "seronegative" RA, at significantly higher frequencies, levels, and co-occurrence

Table 3 RA-associated autoantibodies in "seronegative" RA

\begin{tabular}{lll}
\hline Antibody status $^{\text {a }}$ & $\boldsymbol{n}$ & $\%$ \\
\hline ACPA+/RF+/anti-CarP+ & 10 & 1.9 \\
ACPA+/RF+/anti-CarP- & 12 & 2.3 \\
ACPA+/RF-/anti-CarP+ & 22 & 4.1 \\
ACPA+/RF-/anti-CarP- & 115 & 21.5 \\
ACPA-/RF+/anti-CarP+ & 7 & 1.3 \\
ACPA-/RF+/anti-CarP- & 21 & 3.9 \\
ACPA-/RF-/anti-CarP+ & 46 & 8.6 \\
ACPA-/RF-/anti-CarP- & 301 & 56.4 \\
\hline
\end{tabular}

${ }^{a}$ Antibody status was evaluated in 534 anti-CCP2 IgG-/lgM RF- ElRA patients. $A C P A=$ any ACPA fine-specificity, $R F=\lg A$ and/or IgG RF, anti-CarP $=$ anticarbamylated fibrinogen antibodies compared to controls, and with a similar pattern of reactivity as in traditionally defined seropositive RA, albeit with a narrower serology in regards to RA-associated autoantibodies. Our data are thus in line with previous studies demonstrating the presence of ACPA in antiCCP2-negative RA $[16,17,19]$ and a recent report, detecting IgA RF and anti-CCP2 IgA in $5.2 \%$ of "seronegative" RA [30]. A novel finding in our study is that the extended ACPA/RF serology defines a group of RA patients with a more severe prognosis, and since additional screening of ACPA fine-specificities and IgA/IgG RF was able to identify $35 \%$ of the patients in the conventionally defined seronegative RA subset, our data suggest that the use of such extended serology may be clinically useful.

While the presence of ACPA fine-specificities and RF in "seronegative" RA associated with higher disease activity during follow-up, the presence of anti-CarP antibodies associated with lower disease activity in our study. This observation is somewhat contradictory to what has been reported previously, where presence of anti-CarP antibodies was shown to associate with higher disease activity and worse clinical outcome [21, 31, 32]. However, the other studies have either only analysed baseline DAS28, and at baseline, we also found a nonsignificant trend with higher disease activity in the antiCarP-positive group, or the other studies have analysed radiological progression over time, while we have analysed DAS28 over time, with no access to radiological data. Moreover, the other studies did not investigate presence of ACPA fine-specificities. Based on our data, nearly $40 \%$ of anti-CarP-positive patients within the "seronegative" RA population would also be ACPApositive. Therefore, it cannot be ruled out that the observed joint destruction in the other studies is primarily associated with ACPA, rather than anti-CarP antibodies.

In accordance with data published by Wagner et al. [17], as well as our recent report [19], we found an association of SE with the presence of ACPA in anti-CCP2negative RA, suggesting that these patients belong to the same disease entity as anti-CCP2-positive patients. A more detailed analysis of the ACPA fine-specificity response showed that SE associates primarily with some ACPA fine-specificities, not all. These ACPA finespecificities co-occurred to a large extent, which could possibly indicate cross-reactivity rather than cooccurrence, something that has been shown on a monoclonal level for different ACPA [33-35]. Other ACPA did not co-occur to the same extent, which may suggest different triggering mechanisms for different ACPA finespecificities. This, we have recently explored in a separate study, demonstrating unique genetic characteristics for different ACPA fine-specificities [36]. We did not find an association between HLA-DRB1 SE and RF in 
Table 4 Disease activity during 5-years follow-up, in relation to autoantibody status

\begin{tabular}{|c|c|c|c|c|c|c|c|c|c|}
\hline RA subset $^{a}$ & & $0 \mathrm{~m}$ & $3 \mathrm{~m}$ & $6 \mathrm{~m}$ & $12 \mathrm{~m}$ & $24 \mathrm{~m}$ & $36 \mathrm{~m}$ & $48 \mathrm{~m}$ & $60 \mathrm{~m}$ \\
\hline \multirow[t]{2}{*}{ Seronegative } & DAS28 & 5.10 & 3.49 & 3.25 & 2.72 & 2.33 & 2.14 & 1.96 & 2.2 .11 \\
\hline & $n$ & 163 & 138 & 139 & 154 & 148 & 73 & 47 & 103 \\
\hline \multirow[t]{2}{*}{$\mathrm{Ab}+$} & DAS28 & 5.37 & 3.59 & 3.34 & 2.80 & 2.68 & 2.63 & 2.97 & 2.02 \\
\hline & $n$ & 123 & 110 & 107 & 119 & 104 & 56 & 35 & 62 \\
\hline \multirow[t]{2}{*}{ ACPA+ } & DAS28 & 5.34 & 3.63 & 3.41 & 2.94 & 2.71 & 2.99 & 3.66 & 2.20 \\
\hline & $n$ & 87 & 77 & 79 & 84 & 75 & 40 & 21 & 41 \\
\hline \multirow[t]{2}{*}{ RF+ } & DAS28 & 5.50 & 3.67 & 3.49 & 2.49 & 2.27 & 2.61 & 3.17 & 1.88 \\
\hline & $n$ & 27 & 23 & 23 & 26 & 24 & 13 & 8 & 12 \\
\hline \multirow[t]{2}{*}{ Carb+ } & DAS18 & 5.50 & 3.30 & 3.35 & 2.77 & 2.66 & 2.13 & 2.20 & 1.78 \\
\hline & $n$ & 43 & 38 & 33 & 40 & 33 & 16 & 14 & 24 \\
\hline \multirow[t]{2}{*}{$\mathrm{ACPA}+/ \mathrm{Carb}-$} & DAS28 & 5.15 & 3.66 & 3.44 & 3.01 & 2.76 & 3.23 & 3.69 & 2.37 \\
\hline & $n$ & 68 & 61 & 64 & 67 & 60 & 33 & 16 & 32 \\
\hline \multirow[t]{2}{*}{ ACPA-/Carb+ } & DAS28 & 5.57 & 3.14 & 3.30 & 2.75 & 2.74 & 1.89 & 1.91 & 1.71 \\
\hline & $n$ & 24 & 22 & 18 & 23 & 18 & 9 & 9 & 15 \\
\hline \multirow[t]{2}{*}{ Seropositive } & DAS28 & 5.08 & 3.67 & 3.25 & 3.02 & 2.71 & 2.94 & 2.87 & 2.75 \\
\hline & $n$ & 747 & 650 & 595 & 719 & 685 & 444 & 315 & 522 \\
\hline
\end{tabular}

${ }^{a}$ All RA subsets (with the exception of seropositive RA) are anti-CCP2 lgG-/lgM RF-; Ab+ = ACPA+, and/or lgA RF+, and/or lgG RF+, and/or anti-CarP+; seropositive $=$ anti-CCP2 lgG + and/or IgM RF+. Median DAS28-CRP values are shown for each RA subset (significantly higher DAS28-CRP compared to seronegative $\mathrm{RA}$ in bold). $N=$ number of patients in each subset at each time point. $0 \mathrm{~m}=$ baseline; $3-60 \mathrm{~m}=3 \mathrm{months}$ to $60 \mathrm{months}$ follow-up period

anti-CCP2-negative RA, supporting data generated from single-cell RNA sequencing of RF-positive and ACPApositive $B$ cells, which suggest a $T$ cell-dependent affinity maturation for the generation of ACPA, but innate immune pathways for the generation of RF [37].

We could not detect an association between smoking and presence of ACPA in anti-CCP2-negative RA, but a significant association with $\mathrm{RF}$, in particular IgA RF. We also observed significantly elevated RF (but not anti-CCP2 IgG) levels in current smokers compared to former smokers. These data are thus in line with recent reports, demonstrating a lack of association between ACPA and smoking in RF-negative RA [38] and that the association between smoking and RA-associated antibodies is likely dependent on RF/ RF levels [39]. The association between smoking and IgA RF is well known $[40,41]$ and points to the putative role of mucosal inflammation in the generation of IgA RF. Notably, RF has been reported in healthy smokers [41, 42].

Contrary to ACPA and RF, the other autoantibodiesnot primarily associated with RA-were low in frequency, equally distributed among anti-CCP2-positive and anti-CCP2-negative RA patients, and showed no associations with genetic and environmental risk factors. Most common were anti-R060/SSA and anti-Ro52/SSA antibodies, each with a frequency of around 5\%, similar to previous reports [43]. Their presence may indicate clinical features associated with other systemic inflammatory diseases, in addition to classical RA symptoms.
Although the PTPN22 polymorphism (rs2476601) was more frequent among anti-CCP2-positive patients compared to anti-CCP2-negative, we found a significant association with both subsets, similar to previous reports $[44,45]$. Presence/absence of ACPA fine-specificities, $\mathrm{RF}$, and other autoantibodies did not affect this positive association. PTPN22 polymorphism has been described as a risk factor for several autoimmune diseases [46], and healthy carriers have been reported to have more autoreactive B cells compared to non-carriers [47]. Hence, the association of PTPN22 with autoantibodynegative RA was a bit surprising and potentially suggests the presence of yet other autoimmune reactions.

Our study is by no means complete when it comes to the analysis of RA-associated autoantibodies. We did not investigate the presence of anti-CCP2 IgA [48] nor did we analyse presence of ACPA using other commercial clinical tests, like the CCP3/CCP3.1 assays or the mutated citrullinated vimentin (MCV) assay. The antibody response against human PAD enzymes [49] and acetylated proteins [50] was not investigated either, and antiCarP antibodies were analysed using carbamylated fibrinogen as an antigen [28], while other studies have used carbamylated foetal calf serum [21, 39].

Another point to be considered is the loss of specificity when analysing multiple autoantibody reactivities. Hence, for a diagnostic setting, highly specific cutoff values should be strictly applied to each individual antibody and be based not only on population controls but on disease controls with other rheumatic and 
autoimmune conditions. Still, our data suggest that the number of ACPA fine-specificities, as well as cooccurrence of ACPA and IgA/IgG RF, could be useful diagnostic markers.

\section{Conclusion}

Our study confirms that seronegative RA, defined only from the presence of anti-CCP2 IgG and IgM RF, is not truly a seronegative disease subset. Presence of ACPA and RF in the conventionally defined seronegative RA population defines a group of patients that resemble seropositive patients with respect to risk factors and clinical picture. Thus, our data suggest that extended ACPA and RF serology could be clinically useful in order to capture patients early in the disease process and to identify a subset with a high need for active treatment.

\section{Supplementary information}

Supplementary information accompanies this paper at https://doi.org/10. 1186/s13075-020-02191-2.

Additional file 1: Supplementary Table 1. Citrullinated peptide antigens on the multiplex microarray. The table lists citrullinated antigens used on the multiplex microarray, including name, protein of origin, and amino acid sequence, as well as references.

Additional file 2: Supplementary Table 2. Other (non-citrullinated) autoantigens on the multiplex microarray. The table lists the other antigens used on the multiplex microarray, including name, protein of origin, and major associated disease(s).

Additional file 3: Supplementary Table 3. Baseline characteristics in CCP2-positive and -negative RA. The table show baseline characteristics for the EIRA patients included in the study, based on anti-CCP2 lgG status; $p$-values indicate differences between subsets with respect to: age, female-to-male ratio, number of smokers, HLA-DRB1 SE-positivity, PTPN22-positivity, DAS28 and CRP.

Additional file 4: Supplementary Figure 1. ACPA fine-specificity levels in anti-CCP2-negative RA and controls. ACPA levels for 19 individual ACPA fine-specificities are shown in separate graphs with AU values on the $Y$-axes. Only ACPA levels above cutoff for positivity are shown.

Additional file 5: Supplementary Table 4. Other autoantibodies in anti-CCP2-positive and -negative RA and controls. Frequencies of 17 other autoantibodies in anti-CCP2-positive RA, anti-CCP2-negative RA and controls are shown, as well as median antibody levels in anti-CCP2positive and -negative RA ( $p$-values indicate differences between antiCCP2-negative and anti-CCP2-positive RA subsets).

Additional file 6: Supplementary Table 5. Associations between different autoantibodies and PTPN22 polymorphism, in anti-CCP2negative RA. Odds ratios with 95\% confidence intervals are shown for associations between PTPN22 polymorphism and presence/absence of ACPA, RF, other autoantibodies, or "any autoantibody" in anti-CCP2negative RA.

Additional file 7: Supplementary Table 6. Associations between different ACPA fine-specificities and HLA-DRB1 SE, in anti-CCP2-positive and anti-CCP2-negative RA. Odds ratios with 95\% confidence intervals are shown for associations between HLA-DRB1 SE and presence/absence of 19 different ACPA fine-specificities, in anti-CCP2-positive and -negative RA: $p$-values indicate differences in ORs between ACPA fine-specificitypositive and -negative subsets in the anti-CCP2-positive subset.

Additional file 8: Supplementary Table 7. Associations between RF isotypes and smoking, in anti-CCP2-positive and anti-CCP2-negative RA. Odds ratios with 95\% confidence intervals are shown for associations between smoking and presence/absence of lgM, IgG or IgA RF, in anti-
CCP2-positive and -negative RA; p-values indicate differences in ORs between RF isotype-positive and -negative subsets.

Additional file 9: Supplementary Figure 2. Antibody levels in EIRA RA cases based on smoking status. IgM, lgG and lgA RF levels, as well as anti-CCP2 lgG levels, are shown for never, current and former smokers in all EIRA RA patients where smoking data was available.

\section{Abbreviations}

ACPA: Anti-citrullinated protein antibody; RA: Rheumatoid arthritis; RF: Rheumatoid factor; ACR: American College of Rheumatology; EULAR: European League Against Rheumatism; SE: Shared epitope; CCP: Cyclic citrullinated peptide; Cll: Type II collagen; Anti-CarP antibody: Anti-carbamylated protein antibody; EIRA: Epidemiological investigation of RA; DAS28: Disease activity score for 28 joints; CRP: Creactive protein; hnRNP-A3: Heterogeneous nuclear ribonucleoprotein-A3; OR: Odds ratio; Cl: Confidence interval; MCV: Mutated citrullinated vimentin

\section{Acknowledgements}

We wish to thank EIRA study participants and the EIRA study group for their contributions; Professor Lars Klareskog for establishing the EIRA study: and for support and scientific input; scientists previously involved in the generation of data for the EIRA database: Leonid Padyukov, Patrick Stolt, Camilla Bengtsson, and Lena Israelsson; Per Matsson, Mats Nystrand, and Thomas Schlederer (Thermo Fisher Scientific, Uppsala, Sweden) for their scientific support concerning the multiplex platform; and Karl Andersson for calculating antibody cutoff values.

\section{Authors' contributions}

ER had full access to all data, made statistical calculations, and produced Table 1, Fig. 2, and supplementary Tables 3 and 4. AKH made all unconditional logistic regression analyses for the gene-environment associations and produced Table 2 and supplementary Tables 5, 6, and 7. MH and LMA performed the antibody screening on EIRA, using the peptide multiplex array and EliA ${ }^{\mathrm{TM}}$. BB analysed correlations between ACPAs and produced Fig. 1. SS retrieved clinical data from the Swedish Rheumatology Quality register and performed the linkage with EIRA. MC, PJJ, RH, KS, and GS provided antigen peptides for the antibody analyses, including validation of their performance. LA is responsible for administrating the EIRA study and supervised the work of AKH and BB. JR contributed to the overall study design, analysed antibody levels in patients based on smoking status, analysed DAS28 5-year follow-up data, and produced Table 4. KL conceived the study; supervised the work of ER; produced Table 3, supplementary Tables 1 and 2, and supplementary figure 1; wrote the manuscript together with ER; and had overall responsibility for the study. All authors critically read, reviewed, and approved the final manuscript.

\section{Funding}

This work was supported by grants from the Swedish Research Council (2017-01696); King Gustav V:s 80-year foundation (FAI-2016-0273); the EU funded consortia TRIGGER (FP7-Health-2013-306029); and the EU/EFPIA Innovative Medicines Initiative Joint Undertaking BeTheCure (grant $n^{\circ} 115142$ ), and RTCure (grant $n^{\circ}$ 777357). Open access funding provided by Karolinska Institute.

\section{Availability of data and materials}

All data generated during this study are included in this published article, and in its supplementary information files, or are available from the corresponding author on reasonable request. The EIRA dataset on which the current study is based is deposited in the EIRA database at Karolinska Institutet, Stockholm, Sweden.

\section{Ethics approval and consent to participate}

The study has been performed in compliance with the Declaration of Helsinki, with informed consent obtained from all study participants, and ethical approval granted at the Regional Ethical Review Board in Stockholm.

\section{Consent for publication}

Not applicable. 


\section{Competing interests}

The authors declare that they have no conflicting financial interest and have not received funding from commercial sources in the context of this study. Karolinska Institutet has been a partner with Thermo Fisher Scientific within the Innovative Medicines Initiative BTCure, a public-private partnership between the EU and the European Federation of Pharmaceutical Industries (www.BTcure.eu). Thermo Fisher Scientific has contributed to this consortium with in-kind contributions for the development of the microarray multiplex assay used in the current study. LMA is employed by Thermo Fischer Scientific. JR is a member of the Thermo Fisher Scientific advisory board. $\mathrm{RH}$ is a co-inventor of the patent US Patent 7148 020, protecting the use of the CitC1 and C1 peptides. KS is co-inventor of patents US 13/141,960 and EP 09799354.7, describing the diagnostic use of the hnRNP-A3 peptide epitopes. GS is co-inventor of several international patents about ACPA antigens held by BioMérieux Cy and licenced to Eurodiagnostica Cy and Axis-Shield $\mathrm{Cy}$, for commercialization of the CCP2 assays; according to French laws, part of the royalties is paid to the Toulouse III University and the University Hospital of Toulouse. KL is co-inventor of the patent US12/524,465, describing the diagnostic use of the CEP-1 epitope.

\section{Author details}

${ }^{1}$ Division of Rheumatology, Department of Medicine Solna, Karolinska Institutet, Karolinska University Hospital, CMM L8:04, 17176 Stockholm, Sweden. ${ }^{2}$ Institute of Environmental Medicine, Karolinska Institutet, Stockholm, Sweden. ${ }^{3}$ Department of Clinical Neuroscience, Karolinska Institutet, Stockholm, Sweden. ${ }^{4}$ Thermo Fisher Scientific, Uppsala, Sweden. ${ }^{5}$ Department of Immunology Genetics and Pathology, Uppsala University, Uppsala, Sweden. ${ }^{6}$ Division of Clinical Epidemiology, Department of Medicine Solna, Karolinska Institutet, Stockholm, Sweden. ${ }^{7}$ Faculty of Medicine, School of Health Sciences, University of Iceland, Reykjavik, Iceland. ${ }^{8}$ Unité Différenciation Epithéliale et Autoimmunité Rhumatoïde, Université de Toulouse-INSERM UMR 1056, Toulouse, France. ${ }^{9}$ Section for Medical Inflammation Research, Department of Medical Biochemistry and Biophysics, Karolinska Institutet, Stockholm, Sweden. ${ }^{10}$ Department of Rheumatology and Clinical Immunology, Charité University, Berlin, Germany. ${ }^{11}$ Centre for Occupational and Environmental Medicine, Region Stockholm, Stockholm, Sweden.

Received: 12 September 2019 Accepted: 22 April 2020 Published online: 16 July 2020

\section{References}

1. Aletaha D, Neogi T, Silman AJ, Funovits J, Felson DT, Bingham CO, et al. 2010 rheumatoid arthritis classification criteria: an American College of Rheumatology/European League Against Rheumatism collaborative initiative. Ann Rheum Dis. 2010;69(9):1580-8.

2. Kurreeman F, Liao K, Chibnik L, Hickey B, Stahl E, Gainer V, et al. Genetic basis of autoantibody positive and negative rheumatoid arthritis risk in a multi-ethnic cohort derived from electronic health records. Am J Hum Genet. 2011;88(1):57-69.

3. Padyukov L, Seielstad M, Ong RTH, Ding B, Rönnelid J, Seddighzadeh M, et al. A genome-wide association study suggests contrasting associations in ACPA-positive versus ACPA-negative rheumatoid arthritis. Ann Rheum Dis. 2011;70(2):259-65.

4. Viatte S, Massey J, Bowes J, Duffus K, arcOGEN Consortium, Eyre S, et al. Replication of associations of genetic loci outside the HLA region with susceptibility to anti-cyclic citrullinated peptide-negative rheumatoid arthritis. Arthritis Rheumatol. 2016;68(7):1603-13.

5. Rönnelid J, Wick MC, Lampa J, Lindblad S, Nordmark B, Klareskog L, et al. Longitudinal analysis of citrullinated protein/peptide antibodies (anti-CP) during 5 year follow up in early rheumatoid arthritis: anti-CP status predicts worse disease activity and greater radiological progression. Ann Rheum Dis. 2005;64(12):1744-9.

6. Nordberg LB, Lillegraven S, Lie E, Aga A-B, Olsen IC, Hammer HB, et al. Patients with seronegative RA have more inflammatory activity compared with patients with seropositive RA in an inception cohort of DMARD-naïve patients classified according to the 2010 ACR/EULAR criteria. Ann Rheum Dis. 2017;76(2):341-5.

7. Verschueren P, De Cock D, Corluy L, Joos R, Langenaken C, Taelman V, et al. Patients lacking classical poor prognostic markers might also benefit from a step-down glucocorticoid bridging scheme in early rheumatoid arthritis: week 16 results from the randomized multicenter CareRA trial. Arthritis Res Ther. 2015;17(1):97.

8. van Nies JAB, Krabben A, Schoones JW, Huizinga TWJ, Kloppenburg M, van der Helm-van Mil AHM. What is the evidence for the presence of a therapeutic window of opportunity in rheumatoid arthritis? A systematic literature review. Ann Rheum Dis. 2014;73(5):861-70.

9. Westhoff G, Schneider M, Raspe H, Zeidler H, Runge C, Volmer T, et al. Advance and unmet need of health care for patients with rheumatoid arthritis in the German population--results from the German Rheumatoid Arthritis Population Survey (GRAPS). Rheumatology (Oxford). 2009;48(6):650-7.

10. Masson-Bessière C, Sebbag M, Girbal-Neuhauser E, Nogueira L, Vincent C, Senshu T, et al. The major synovial targets of the rheumatoid arthritisspecific antifilaggrin autoantibodies are deiminated forms of the alpha- and beta-chains of fibrin. J Immunol. 2001;166(6):4177-84.

11. Vossenaar ER, Després N, Lapointe E, van der Heijden A, Lora M, Senshu T, et al. Rheumatoid arthritis specific anti-Sa antibodies target citrullinated vimentin. Arthritis Res Ther. 2004;6(2):R142-50.

12. Burkhardt $H$, Sehnert B, Bockermann R, Engström A, Kalden JR, Holmdahl R, Humoral immune response to citrullinated collagen type II determinants in early rheumatoid arthritis. Eur J Immunol. 2005;35(5):1643-52.

13. Lundberg K, Kinloch A, Fisher BA, Wegner N, Wait R, Charles P, et al. Antibodies to citrullinated alpha-enolase peptide 1 are specific for rheumatoid arthritis and cross-react with bacterial enolase. Arthritis Rheum. 2008:58(10):3009-19.

14. Sokolove J, Bromberg R, Deane KD, Lahey L, Derber LA, Chandra PE, et al. Autoantibody epitope spreading in the pre-clinical phase predicts progression to rheumatoid arthritis. PLoS One. 2012;7(5):e35296.

15. Schwenzer A, Jiang X, Mikuls TR, Payne JB, Sayles HR, Quirke A-M, et al. Identification of an immunodominant peptide from citrullinated tenascin- $C$ as a major target for autoantibodies in rheumatoid arthritis. Ann Rheum Dis. 2016;75(10):1876-83.

16. Lundberg K, Bengtsson C, Kharlamova N, Reed E, Jiang X, Källberg H, et al. Genetic and environmental determinants for disease risk in subsets of rheumatoid arthritis defined by the anticitrullinated protein/peptide antibody fine specificity profile. Ann Rheum Dis. 2013;72(5):652-8.

17. Wagner CA, Sokolove J, Lahey LJ, Bengtsson C, Saevarsdottir S, Alfredsson L, et al. Identification of anticitrullinated protein antibody reactivities in a subset of anti-CCP-negative rheumatoid arthritis: association with cigarette smoking and HLA-DRB1 'shared epitope' alleles. Ann Rheum Dis. 2015;74(3): 579-86.

18. Hansson M, Mathsson L, Schlederer T, Israelsson L, Matsson P, Nogueira L, et al. Validation of a multiplex chip-based assay for the detection of autoantibodies against citrullinated peptides. Arthritis Res Ther. 2012;14(5): R201.

19. Rönnelid J, Hansson M, Mathsson-Alm L, Cornillet M, Reed E, Jakobsson P-J, et al. Anticitrullinated protein/peptide antibody multiplexing defines an extended group of ACPA-positive rheumatoid arthritis patients with distinct genetic and environmental determinants. Ann Rheum Dis. 2018; 77(2):203-11.

20. Vallbracht I, Rieber J, Oppermann M, Förger F, Siebert U, Helmke K. Diagnostic and clinical value of anti-cyclic citrullinated peptide antibodies compared with rheumatoid factor isotypes in rheumatoid arthritis. Ann Rheum Dis. 2004;63(9):1079-84.

21. Shi J, Knevel $R$, Suwannalai $P$, van der Linden MP, Janssen GMC, van Veelen PA, et al. Autoantibodies recognizing carbamylated proteins are present in sera of patients with rheumatoid arthritis and predict joint damage. Proc Natl Acad Sci U S A. 2011;108(42):17372-7.

22. Peene I, Meheus L, Veys EM, De Keyser F. Diagnostic associations in a large and consecutively identified population positive for anti-SSA and/or antiSSB: the range of associated diseases differs according to the detailed serotype. Ann Rheum Dis. 2002;61(12):1090-4.

23. Arnett FC, Edworthy SM, Bloch DA, McShane DJ, Fries JF, Cooper NS, et al. The American Rheumatism Association 1987 revised criteria for the classification of rheumatoid arthritis. Arthritis Rheum. 1988;31(3):315-24.

24. Stolt P, Bengtsson C, Nordmark B, Lindblad S, Lundberg I, Klareskog L, et al. Quantification of the influence of cigarette smoking on rheumatoid arthritis: results from a population based case-control study, using incident cases. Ann Rheum Dis. 2003;62(9):835-41.

25. Padyukov L, Silva C, Stolt P, Alfredsson L, Klareskog L. A gene-environment interaction between smoking and shared epitope genes in HLA-DR 
provides a high risk of seropositive rheumatoid arthritis. Arthritis Rheum. 2004:50(10):3085-92.

26. Plenge RM, Padyukov L, Remmers EF, Purcell S, Lee AT, Karlson EW, et al. Replication of putative candidate-gene associations with rheumatoid arthritis in $>4,000$ samples from North America and Sweden: association of susceptibility with PTPN22, CTLA4, and PADI4. Am J Hum Genet. 2005;77(6): 1044-60.

27. Saevarsdottir S, Wedrén S, Seddighzadeh M, Bengtsson C, Wesley A, Lindblad $\mathrm{S}$, et al. Patients with early rheumatoid arthritis who smoke are less likely to respond to treatment with methotrexate and tumor necrosis factor inhibitors: observations from the Epidemiological Investigation of Rheumatoid Arthritis and the Swedish Rheumatology Register cohorts. Arthritis Rheum. 2011;63(1):26-36.

28. Jiang $X$, Trouw LA, van Wesemael TJ, Shi J, Bengtsson C, Källberg H, et al. Anti-CarP antibodies in two large cohorts of patients with rheumatoid arthritis and their relationship to genetic risk factors, cigarette smoking and other autoantibodies. Ann Rheum Dis. 2014;73(10):1761-8.

29. Klareskog L, Stolt P, Lundberg K, Källberg H, Bengtsson C, Grunewald J, et al. A new model for an etiology of rheumatoid arthritis: smoking may trigger HLA-DR (shared epitope)-restricted immune reactions to autoantigens modified by citrullination. Arthritis Rheum. 2006;54(1):38-46.

30. Sieghart D, Platzer A, Studenic P, Alasti F, Grundhuber M, Swiniarski S, et al. Determination of autoantibody isotypes increases the sensitivity of serodiagnostics in rheumatoid arthritis. Front Immunol. 2018;9:876.

31. Truchetet M-E, Dublanc S, Barnetche T, Vittecoq O, Mariette X, Richez C, et al. Association of the presence of anti-carbamylated protein antibodies in early arthritis with a poorer clinical and radiologic outcome: data from the French ESPOIR cohort. Arthritis Rheumatol. 2017;69(12):2292-302.

32. Derksen VFAM, Trouw LA, Huizinga TWJ, van der Helm-van Mil AHM, Knevel $\mathrm{R}$, Westerlind $\mathrm{H}$, et al. Anti-carbamylated protein antibodies and higher baseline disease activity in rheumatoid arthritis-a replication study in three cohorts: comment on the article by Truchetet et al. Arthritis Rheumatol. 2018;70(12):2096-7.

33. Steen J, Forsström B, Sahlström P, Odowd V, Israelsson L, Krishnamurthy A, et al. Recognition of amino acid motifs, rather than specific proteins, by human plasma cell-derived monoclonal antibodies to posttranslationally modified proteins in rheumatoid arthritis. Arthritis Rheumatol. 2019;71(2): 196-209.

34. Elliott SE, Kongpachith S, Lingampalli N, Adamska JZ, Cannon BJ, Mao R, et al. Affinity maturation drives epitope spreading and generation of proinflammatory anti-citrullinated protein antibodies in rheumatoid arthritis. Arthritis Rheumatol. 2018;70(12):1946-58.

35. Ge C, Xu B, Liang B, Lönnblom E, Lundström SL, Zubarev RA, et al. Structural basis of cross-reactivity of anti-citrullinated protein antibodies. Arthritis Rheumatol. 2019;71(2):210-21.

36. Terao C, Brynedal B, Chen Z, Jiang X, Westerlind H, Hansson M, et al. Distinct HLA associations with rheumatoid arthritis subsets defined by serological subphenotype. Am J Hum Genet. 2019; in press. https://doi.org/ 10.1016/j.ajhg.2019.08.002.

37. Lu DR, McDavid AN, Kongpachith S, Lingampalli N, Glanville J, Ju C-H, et al. $T$ cell-dependent affinity maturation and innate immune pathways differentially drive autoreactive $B$ cell responses in rheumatoid arthritis. Arthritis Rheumatol. 2018;70(11):1732-44.

38. Murphy D, Mattey D, Hutchinson D. Anti-citrullinated protein antibody positive rheumatoid arthritis is primarily determined by rheumatoid factor titre and the shared epitope rather than smoking per se. PLoS One. 2017; 12(7): $\mathrm{e} 0180655$.

39. van Wesemael TJ, Ajeganova S, Humphreys J, Terao C, Muhammad A, Symmons DPM, et al. Smoking is associated with the concurrent presence of multiple autoantibodies in rheumatoid arthritis rather than with anticitrullinated protein antibodies per se: a multicenter cohort study. Arthritis Res Ther. 2016;18(1):285-10.

40. Mikuls TR, Hughes LB, Westfall AO, Holers VM, Parrish L, van der Heijde $D$, et al. Cigarette smoking, disease severity and autoantibody expression in African Americans with recent-onset rheumatoid arthritis. Ann Rheum Dis. 2008;67(11):1529-34

41. Janssen KMJ, de Smit MJ, Brouwer E, de Kok FAC, Kraan J, Altenburg J, et al. Rheumatoid arthritis-associated autoantibodies in non-rheumatoid arthritis patients with mucosal inflammation: a case-control study. Arthritis Res Ther. 2015;17(1):174.
42. Korpilahde T, Heliövaara M, Knekt P, Marniemi J, Aromaa A, Aho K. Smoking history and serum cotinine and thiocyanate concentrations as determinants of rheumatoid factor in non-rheumatoid subjects. Rheumatology (Oxford). 2004;43(11):1424-8.

43. Schneeberger E, Citera G, Heredia M, Maldonado CJ. Clinical significance of anti-Ro antibodies in rheumatoid arthritis. Clin Rheumatol. 2008;27(4):517-9.

44. Viatte S, Plant D, Bowes J, Lunt M, Eyre S, Barton A, et al. Genetic markers of rheumatoid arthritis susceptibility in anti-citrullinated peptide antibody negative patients. Ann Rheum Dis. 2012;71(12):1984-90.

45. Bossini-Castillo L, de Kovel C, Källberg H, van 't Slot R, Italiaander A, Coenen $M$, et al. A genome-wide association study of rheumatoid arthritis without antibodies against citrullinated peptides. Ann Rheum Dis. 2015;74(3):e15.

46. Zheng J, Ibrahim S, Petersen F, Yu X. Meta-analysis reveals an association of PTPN22 C1858T with autoimmune diseases, which depends on the localization of the affected tissue. Genes Immun. 2012;13(8):641-52.

47. Menard L, Saadoun D, Isnardi I, Ng Y-S, Meyers G, Massad C, et al. The PTPN22 allele encoding an R620W variant interferes with the removal of developing autoreactive B cells in humans. J Clin Invest. 2011;121(9):363544.

48. Svärd A, Skogh T, Alfredsson L, llar A, Klareskog L, Bengtsson C, et al. Associations with smoking and shared epitope differ between IgA- and IgGclass antibodies to cyclic citrullinated peptides in early rheumatoid arthritis. Arthritis Rheumatol. 2015;67(8):2032-7.

49. Harris ML, Darrah E, Lam GK, Bartlett SJ, Giles JT, Grant AV, et al. Association of autoimmunity to peptidyl arginine deiminase type 4 with genotype and disease severity in rheumatoid arthritis. Arthritis Rheum. 2008;58(7):1958-67.

50. Juarez M, Bang H, Hammar F, Reimer U, Dyke B, Sahbudin I, et al. Identification of novel antiacetylated vimentin antibodies in patients with early inflammatory arthritis. Ann Rheum Dis. 2016;75(6):1099-107.

\section{Publisher's Note}

Springer Nature remains neutral with regard to jurisdictional claims in published maps and institutional affiliations.
Ready to submit your research? Choose BMC and benefit from:
- fast, convenient online submission
- thorough peer review by experienced researchers in your field
- rapid publication on acceptance
- support for research data, including large and complex data types
- gold Open Access which fosters wider collaboration and increased citations
- maximum visibility for your research: over $100 \mathrm{M}$ website views per year
At BMC, research is always in progress.
Learn more biomedcentral.com/submissions 